\title{
EDITORIAL
}

\section{The problem with representing knowledge with and about technology}

The articles contained in this issue raise a series of questions that all, to a greater or lesser degree, call in to doubt our ability to communicate with each other. This is a particularly melodramatic way of expressing it, perhaps, but it serves to highlight a fundamental concern: even if we know something, can we share that knowledge with anyone else? More specifically, for researchers in this field, if we think we know something about technology, how can we communicate that understanding to others?

The general problems of communication are illustrated by a series of articles from Dickey, Wheeler, Lee et al. and by Bakker et al. There are many things that teachers find hard to communicate to students in the first place, particularly those that relate to tacit practices. Dickey's study explores one way in which such practices can be communicated to students - involving an embodied representation of knowledge, communication through demonstration.

However, even if we work out how to represent what we value to our students, they will gain no credit for what they learn unless they can communicate it back to us, especially in a form suitable for assessment. Even formatively, it would be very hard to give feedback to a student who could not explain to a tutor what they currently understood, at least in some form or another. Laurillard's (2001) conversational framework serves to illustrate this point clearly; with one-half of the interactions missing, there could be little hope of reciprocal dialogue.

So do we support them in acquiring the communicational practices we prefer, for example, by using graphic organisers to improve their academic writing, as Lee et al. propose? Do we open up our own communicational repertoire, as teachers, to adopt a form of communication in which many students are already fluent, such as Instant Messenging? (Bakker et al.'s work calls into question, however, whether students would like us to do this even if we wanted to.) Irrespective of what we do, can any of these approaches offer some educational advantage that makes them better than our default position of face-to-face communication? Wheeler's analysis suggests that, for some people, under certain conditions, perhaps they can. Without making sweeping generalisations, such work begins to identify implications for the way we design educational experiences.

Tompsett calls us to practice reflexivity in our research work, and the point is particularly apt here. These communicational issues do not just exist for our students; 
they are real issues for researchers in this field too. There is considerable interest, and no small amount of funding, in developing ways to represent and share educational practice. Whether these representations are expressed as case studies, instantiated as toolkits, turned into formalised design patterns, modelled as use cases, and so on, a hidden assumption is that some pedagogy, some value, can be communicated from the designer to a teacher, and perhaps further to a learner. Falconer's article raises questions about how and if this can be achieved. However we try to express our understanding, if the experiences of our audience are too remote it will be hard or even impossible to make ourselves understood. Falconer argues that even closely related communities can be far enough apart that they struggle to communicate with each other.

Our discussion section develops this point. Previously, we published Pam Moule's article outlining a model intended to help tutors engage with the pedagogy of elearning. When explaining this model, she found it helpful to draw a contrast with Salmon's five-step model for e-learning. In this issue, each takes a turn to explain why their model was necessary; each ends by inviting further debate and discussion that will - they propose - allow our understanding of e-learning to develop. Tompsett has also written in $A L T-\mathcal{f}$ about our attempts to represent knowledge about e-learning, and hence we invited him to offer a third perspective on this discussion. Like Falconer, he suggests that even when we share intentions-even where we appear to share the same terminology - we may end up talking past each other, neither party quite communicating what they intended.

This is not, he proposes, a problem that can just be solved. It is, however, a problem we can all engage with. Recognising the problem is a good first step towards this.

\section{Martin Oliver \\ Institute of Education, UK}

\section{References}

Laurillard, D. (2001) Rethinking university teaching: a framework for the effective use of educational technology (London, Routledge). 